\title{
THE PRODUCTION OF ERYTHEMA OF THE SKIN BY EXPOSURE TO X-RAY RADIATION
}

\author{
ALBERT G. RICHARDS, B.S., M.S. \\ School of Dentistry, University of Michigan, Ann Arbor, Mich.
}

$\mathrm{O}^{\mathrm{N}}$ NE manifestation of overexposure of the skin to $x$-ray radiation employed diagnostically is the appearance of an erythema similar to sunburn. This paper presents the experimental results of a study which was completed to determine the amount of radiation from a dental x-ray machine that is required to produce an erythema of the skin on the flexor surface of the forearm.

There are many references in dental literature which state that an exposure of 1,200 milliampere seconds* at a target-skin distance of 8 inches will cause an erythema of the skin; therefore, no single area of skin should be exposed to more than one-half of the erythema dose, or $600 \mathrm{Ma}$.S., in any two-week period. To test the validity of these statements, circular areas of skin, $11 / 8$ inches in diameter, were exposed on the flexor surface of the forearms of 20 male volunteers of college age.

In the beginning phase of this investigation, exposures were initially of short duration and then were gradually lengthened to approach the exposure time necessary to produce a clearly defined pink area on the forearm. The smallest exposure found to produce an erythema was 425 Ma.S., although many subjects did not experience an erythema until they had received 550 to $600 \mathrm{Ma}$.S. of exposure to $x$-ray radiation. After the approximate magnitude of the exposure required to produce erythema had been determined, a second series of tests was performed on nineteen additional male volunteers of college age in an effort to determine more exactly the amount of radiation from a dental x-ray machine that is required to produce an erythema of the skin on the flexor surface of the forearm.

Each subject was given 600 Ma.S. of x-ray exposure, which was administered to a circular area on the flexor surface of one forearm. This area was observed again in twenty-four hours. If an erythema had appeared, a similar area on the flexor surface of the other arm was given 10 per cent less exposure, or 540 Ma.S. If no erythema had appeared, the other arm was given 10 per cent more exposure, or $660 \mathrm{Ma}$.S. The initial appearance of the erythema was determined by the subject. The results of the experiments with these nineteen individuals are listed in Table I.

Six of the nineteen subjects did not cooperate to the extent of permitting the second arm to be exposed. However, even the exposure of one arm provided

This study was made possible by a grant from the Faculty Research Fund of the University of Michigan.

Received for publication, Oct. 29, 1953.

* "Milliampere seconds" (abbreviated Ma.S.) is the unit of x-ray exposure or dose which is the product of the number of milliamperes of current flowing through the $x$-ray tube and the duration of the exposure expressed in seconds. 
some useful information. If an erythema of the skin resulted from a $600 \mathrm{Ma}$.S. exposure, it ean be assumed that a similar reaction would result also from a 660 Ma.S. exposure. If no erythema of the skin resulted from a $600 \mathrm{Ma}$.S. exposure, it can be assumed that no reaction would result from an exposure of 540 Ma. S.

TABLE I

Reaction of the Skin to X-ray Radiation

\begin{tabular}{|c|c|c|c|}
\hline SUBJEOT & 540 MA.S. & 600 MA.S. & 660 MA.S. \\
\hline 1 & & + & \\
\hline 2 & & - & \\
\hline 3 & - & + & \\
\hline 4 & + & + & \\
\hline 5 & + & + & \\
\hline 6 & + & + & \\
\hline 7 & + & + & \\
\hline 8 & & + & \\
\hline 9 & + & + & \\
\hline 10 & & - & + \\
\hline 11 & - & + & ? \\
\hline 12 & & - & - \\
\hline 13 & - & + & \\
\hline 14 & + & + & \\
\hline 15 & & - & + \\
\hline 16 & & - & \\
\hline 17 & & + & \\
\hline 18 & & + & \\
\hline 19 & - & + & \\
\hline
\end{tabular}

Not more than 540 Ma.S. of exposure was necessary to produce an erythema in six of fifteen subjects or 40 per cent. Not more than 600 Ma.S. of exposure was necessary to produce an erythema in fourteen of nineteen subjects (73.7 per cent). Not more than $660 \mathrm{Ma}$.S. of exposure was necessary to produce an erythema in sixteen of seventeen subjects ( 94.2 per cent).

The erythema appeared in two to eight hours after the skin was exposed and remained visible until the third to fifth day, at which time tanning or pigmentation replaced the erythema. The phase of pigmentation was of four to eighteen weeks' duration. Alopecia (loss of hair) did not develop at any time in the test sites.

A modern dental x-ray unit, operated at $65 \mathrm{KVP}$ and $10 \mathrm{Ma}$, was used throughout this study. The inherent filtration of the unit was approximately $1 \mathrm{~mm}$. of aluminum. No additional filtration was employed. The x-ray unit delivered $165 \mathrm{r}$ per minute in air as measured opposite the tip of the pointed plastic cone at a distance of $7 \frac{1}{2}$ inches from the focal spot of the $\mathrm{x}$-ray tube. The half-value layer of the radiation was $0.7 \mathrm{~mm}$. of aluminum.

The output of an $x$-ray machine can be measured in air at any specified position by means of a suitable measuring device. If the body of a patient or phantom is introduced into the beam, so that the skin or the surface of the phantom is at this same position, the number of roentgens per minute at this position is increased, because of a scattering of the radiation back from the underlying material. This back-scattering varies with the quality of the radiation, the diameter of the $\mathrm{x}$-ray beam, and the depth of scattering material 
present. $^{1}$ The skin dose is the amount of radiation the skin receives and is the sum of the radiation from the $x$-ray machine measured in air and the backscatter.

From measurements made on a water-filled phantom ( 6 inches by 6 inches by $3^{1 / 2}$ inches deep), it was found that $100 \mathrm{r}$ measured in air equals a skin dose of $104 \mathrm{r}$ when an $\mathrm{x}$-ray beam 11/8 inches in diameter is employed, and $109 \mathrm{r}$ when the beam is 4 inches in diameter. At a focal-skin distance of $7 \frac{1}{2}$ inches, it was found that $600 \mathrm{Ma} . \mathrm{S}$. produced an erythema of the skin on the flexor surface of the forearm in about three-quarters of the subjects. For the x-ray machine used in this study, a $600 \mathrm{Ma} . \mathrm{S}$. exposure equaled $165 \mathrm{r}$ measured in air, or a skin dose of $172 \mathrm{r}$ when the diameter of the beam was limited to $11 / 8$ inches. With the 4-inch diameter beam, the skin dose would be $180 \mathrm{r}$.

Belisario, ${ }^{2}$ Erskine, $^{3}$ and Herrmann ${ }^{4}$ have found that parts of the body ordinarily covered with elothing are more sensitive to $\mathrm{x}$-ray radiation than exposed areas like the face or hands, with their thicker skin. In the present study, only the skin on the flexor surface of the forearm was tested. Therefore, no experimental information is available regarding the quantitative difference in sensitivity to $\mathrm{x}$-ray radiation between the skin on the face and the flexor surface of the forearm. However, it can be reasoned that a $400 \mathrm{Ma}$.S. exposure which produced no reaction on the flexor surface of the forearm could likewise be tolerated by the less sensitive skin of the face. When the x-ray machine involved in these tests is used for dental radiography, it exposes a circular area of skin of about 4 inches in diameter on the face. It had been determined experimentally that the amount of back-seattering increased about 5 per cent when the diameter of the irradiated area was increased from $11 / 8$ to 4 inches. The increase in the skin dose on the face incurred through the use of the large diameter $x$-ray beam would nullify partially the factor of the skin on the face being less sensitive to x-ray radiation than on the flexor surface of the forearm. Any remaining portion of this factor involving the variation in sensitiveness to $x$-ray of the two skin areas can be considered a factor of safety to allow for idiosyncrasy of the patient to radiation and mechanical variations among dental $\mathrm{x}$-ray machines. Therefore, it is suggested that no one area of the face be exposed at a $7 \frac{1}{2}$ inch target-skin distance to more than $400 \mathrm{Ma}$.S. in any twoweek period. No experimental evidence has been presented regarding the time element of a "two-week period." This period of time is advocated here, just as it is throughout the dental literature, because no new evidence has been offered to sustain or refute this commonly accepted period of time.

\section{SUMMARY}

Experiments performed on human skin irradiated with a modern dental $x$-ray machine indicate that an erythema of the skin on the flexor surface of the forearm can be produced by an exposure of $600 \mathrm{Ma.S}$. ("165 $\mathrm{r}$ in air"). Such exposure produced an erythema on three of four patients. The least exposure required to produce an erythema on anyone in these tests was $425 \mathrm{Ma} . \mathrm{S}$. Recognizing that the skin of the face is less sensitive to x-ray radiation than 
the skin on the flexor surface of the forearm and utilizing this difference in sensitivity as a safety factor, it has been recommended that no single area of the face be exposed at a $71 / 2$ inch target-skin distance to more than $400 \mathrm{Ma} . \mathrm{S}$. ("110 $\mathrm{r}$ in air") in any two-week period.

\section{REFERENCES}

1. Glasser, O.: Physical Foundations of Radiology, New York, 1944, Paul B. Hoeber, Inc., p. 211.

2. Belisario, J. C.: Threshold Erythema Dose of Roentgen Rays, Arch. Dermat. \& Syph. 45: $641-669,1942$

3. Erskine, A. W.: Practical X-ray Treatment, St. Paul, 1947, The Bruce Publishing Company, p. 76 .

4. Herrmann, J. B., and Pack, G. T.: Variations in Sensitiveness of Different Skin Areas to the Erythema Dose of Roentgen Radiation, Am. J. Roentgenol. 51: 504-507, 1944. 